Globus An International Journal of Management \& IT A Refereed Research Journal

Vol 11 / No 1 / Jul-Dec 2019 ISSN: 0975-721X

\title{
KNOWLEDGE MANAGEMENT ON POLLUTION AND ENVIRONMENTAL DEGRADATION
}

\author{
*Sukriti Anand \\ *Tanya Sharma
}

\begin{abstract}
Our environment is deteriorating for the last two centuries and almost every part of the planet has been touched by it in one way or the other. The primary cause of environmental degradation is human disturbance. The industrial revolution of 19th century mechanized the production and manufacturing of goods and introduced the use of machinery and other heavy equipments - which in turn, used fuels as source of energy, which deteriorate the environment. The modern technological progress, for which we are so proud of, is actually the root cause of the environmental deterioration. Environmental changes are based on factors like urbanization, population and economic growth, increase in energy consumption and agricultural intensification. The degradation has adverse impacts on humans, plants, animals and micro-organisms. To cope up with the critical situation, we need to make optimum use and management of resources, sustainable development, adoption of green concept and above all community participation in all developmental activities. This article discusses and provides knowledge management related to various factors of pollution and its impact on today environment degradation.

Keywords: Pollution, Degradation, Environment.
\end{abstract}

\section{Introduction}

Environment is the surroundings in which we live. But the contamination of our environment by pollutants is environmental pollution. The current stage of the earth that we are seeing is the cause of centuries of exploitation of earth and its resources. Environmental pollution is characterized as "the sullying of the physical and organic parts of the earth/air framework to such a degree, that ordinary environmental procedures are antagonistically influenced." Pollutants can be normally happening substances or energies, yet they are viewed as contaminants when in abundance of regular levels. Any utilization of characteristic assets at a rate higher than nature's ability to reestablish itself can bring about pollution of air, water, and land. Environmental pollution is gone head to head with the unsustainable anthropogenic exercises, bringing about significant general medical issues. (Khan, 2004). McGeehin et al, (2004) revealed that U.S. populace from irresistible ailments to illnesses, for example, malignancy, birth deformities, and asthma, a significant number of which might be related with environmental exposures. Pollution is something that we face on an ordinary premise; most likely, this is something we may even be safe to in our quick paced lives.[1] There are three significant sorts of environmental pollution: air, water, and land pollution. Air and commotion pollution are expanding at a disturbing rate today. Air pollution happens with the expansion of hurtful synthetics into the Earth's climate. The principle contaminations that reason air pollution are carbon monoxide, Chlorofluorocarbons, nitrogen oxides, and sulfur dioxide. Water pollution is caused when wastes are discharged into the water, which sullies it.

\footnotetext{
* Faculty, GD Goenka Public School, Ghaziabad, UP. Email: sukriti373@gmail.com \& sharma.tanya12345@gmail.com
} 
Soil can even be tainted because of different local and modern exercises. Clamor pollution is

\section{Environmental Pollution}

Pollution, also called environmental pollution, the addition of any substance say solid, liquid, or gas or any form of energy such as heat, sound, radioactivity to the environment at a rate faster than it can be dispersed, diluted, decomposed, recycled, or stored in some harmless form.

\section{Major Types of Pollution}

\section{a. Air Pollution}

Air pollution refers to the release of pollutants into the air that are detrimental to human health and the planet as a whole.

\section{What Causes Air Pollution?}

Burning fossil fuels releases gases and chemicals into the air. And in an especially destructive feedback loop, air pollution not only contributes to climate change but is also exacerbated by it. Air pollution in the form of carbon dioxide and methane raises the earth's temperature.

\section{Effects of Air Pollution}

- Smog and soot-These two are the most prevalent types of air pollution. Smog, or "ground-level ozone," as it is more wonkily called, occurs when emissions from combusting fossil fuels react with sunlight. Soot, or "particulate matter," is made up of tiny particles of chemicals, soil, smoke, dust, or allergens, in the form of gas or solids, that are carried in the air. Smog can irritate the eyes and throat and also damage the lungsespecially of people who work or exercise outside, children, and senior citizens. It's even worse for people who have asthma or allergies-these extra pollutants only intensify their symptoms and can trigger asthma attacks.

- Hazardous air pollutants-These are either deadly or have severe health risks even in small amounts. Almost 200 are regulated by law; some of the most common are mercury, lead, dioxins, and benzene. Polycyclic aromatic hydrocarbons, or PAHs, are toxic components of traffic exhaust and wildfire smoke. In large amounts, they have been linked to eye and lung irritation, blood and liver issues, and even cancer. In one recent additionally a current environmental issue that causes hurt in different manners.[4]

study, the children of mothers who'd had higher PAH exposure during pregnancy had slower brain processing speeds and worse symptoms of ADHD.

- Pollen and mold-Mold and allergens from trees, weeds, and grass are also carried in the air, are exacerbated by climate change, and can be hazardous to health. They are not regulated by the government and are less directly connected to human actions, but they can be considered air pollution. Pollen allergies are worsening because of climate change. Climate change also extends the pollen production season, and some studies are beginning to suggest that ragweed pollen itself might be becoming a more potent allergen. That means more people will suffer runny noses, fevers, itchy eyes, and other symptoms.

\section{How to Help Reduce Air Pollution}

- The less gasoline we burn, the better we're doing to reduce air pollution and harmful effects of climate change.

- Make good choices about transportation. When you can, walk, ride a bike, or take public transportation. For driving, choose cars that get better miles per gallon of gas or choose an electric car.

- You can also investigate your power provider options-you may be able to request that your electricity be supplied by wind or solar.

- Buying your food locally cuts down on the fossil fuels burned in trucking or flying food in from across the country.

\section{b. Water Pollution}

It defined as the presence in groundwater of toxic chemicals and biological agents that exceed what is naturally found in the water and may pose a threat to human health and/or the environment. Additionally, water pollution may consist of chemicals introduced into the water bodies as a result of various human activities. Any amount of those chemicals pollutes the water, regardless of the harm they may pose to human health and the environment.

What Causes Water Pollution? 
Most water pollution doesn't begin in the water itself. Take the oceans: around 80 percent of ocean pollution enters our seas from the land. Virtually any human activity can have an effect on the quality of our water environment. When farmers fertilize the fields, the chemicals they use are gradually washed by rain into the groundwater or surface waters nearby. Sometimes the causes of water pollution are quite surprising. Chemicals released by smokestacks (chimneys) can enter the atmosphere and then fall back to earth as rain, entering seas, rivers, and lakes and causing water pollution.

\section{Effects of Water Pollution}

- Groundwater contamination from pesticides causes reproductive damage within wildlife in ecosystems.

- Sewage, fertilizer, and agricultural run-off contain organic materials that when discharged into waters, increase the growth of algae, which causes the depletion of oxygen. The low oxygen levels are not able to support most indigenous organisms in the area and therefore upset the natural ecological balance in rivers and lakes.

- Swimming in and drinking contaminated water causes skin rashes and health problems like cancer, reproductive problems, typhoid fever and stomach sickness in humans.

- Industrial chemicals and agricultural pesticides that end up in aquatic environments can accumulate in fish that are later eaten by humans. Fish are easily poisoned with metals that are also later consumed by humans. Mercury is particularly poisonous to small children and women. Mercury has been found to interfere with the development of the nervous system in fetuses and young children.

- Ecosystems are destroyed by the rising temperature in the water, as coral reefs are affected by the bleaching effect due to warmer temperatures. Additionally, the warm water forces indigenous water species to seek cooler water in other areas, causing an ecological damaging shift of the affected area.

- Human-produced litter of items such as plastic bags and 6-pack rings can get aquatic animals caught and killed from suffocation.
- Water pollution causes flooding due to the accumulation of solid waste and soil erosion in streams and rivers.

- Oil spills in the water causes animal to die when they ingest it or encounter it. Oil does not dissolve in water so it causes suffocation in fish and birds.

\section{How to Help Reduce Water Pollution}

- We should strictly follow all the laws regarding water pollution - Apart from the laws, creating awareness about the impacts of water pollution is required. Through public awareness and effective implementation of established laws, water pollution can be reduced very effectively.

- Industries should behave more responsibly Many industries directly flow their waste everywhere which reaches rivers through rain water. To prevent water pollution from industrial wastes, it is required that these wastes should be disposed of properly. Some industries follow this rule, and they either destroy the remaining material, or reuse it safely.

- Avoiding hazardous material- It is also extremely important to adopt the correct methods of the disposal of toxic wastes. In the places where paints, cleaning and stain removal chemicals are used, it is required to arrange for the safe disposal of the wastes and the contaminated water coming out of these factories. Oil spill from cars, other vehicles and the machines are required to be stopped completely.

- Cleaning of drains- To prevent water pollution, the drains are required to be cleaned on a regular basis. In the rural areas, pucca drains are required to be made, because the water is going everywhere in a chaotic manner; it finally reaches the rivers and canals with tons of garbage and pollutants. We should develop a technology to keep the drains away from the water sources.

\section{c. Noise Pollution}

A form and level of environmental sound that is generally considered likely to annoy, distract or even harm other people. Most industrial plants operated by a business located near a residential area will need to be respectful of others residing within earshot regarding their production of noise pollution also called sound pollution. 


\section{What Causes Noise Pollution?}

Sound is a necessity in our day-to-day lives, but not noise. Noise is broadly an undesirable sound or sound which generates horrible discomfort to ears noise pollution lacks the element of accumulation in the environment. It merely occurs when sounds waves of intense pressure reach the human ears and may even affect the body muscles due to sound vibrations. Even though noise pollution does not cause death, it can create a lot of discomforts.

\section{Effects of Noise Pollution}

- Hearing Problems: Any unwanted sound that our ears have not been built to filter can cause problems within the body. Our ears can take in a certain range of sounds without getting damaged. Constant exposure to loud levels of noise can easily result in the damage of our ear drums and loss of hearing. It also reduces our sensitivity to sounds that our ears pick up unconsciously to regulate our body's rhythm.

- Health Issues: Excessive noise pollution in working areas such as offices, construction sites, bars and even in our homes can influence psychological health. Studies show that the occurrence of aggressive behavior, disturbance of sleep, constant stress, fatigue and hypertension can be linked to excessive noise levels.

- Sleeping Disorders: Loud noise can certainly hamper your sleeping pattern and may lead to irritation and uncomfortable situations.

- Cardiovascular Issues: Blood pressure levels, cardio-vascular disease and stress related heart problems are on the rise. Studies suggest that high intensity noise causes high blood pressure and increases heart beat rate as it disrupts the normal blood flow.

- Effect on Wildlife: Wildlife faces far more problems than humans because noise pollution since they are more dependent on sound. Animals develop a better sense of hearing than us since their survival depends on it.

\section{How to Help Reduce Noise Pollution}

- Stay away from Noisy area - Noise producing industries, airports, vehicles should be far from residential areas as it very dangerous for infants and senior citizens.
- Follow the Limits of Noise levelCommunity law should check use of loudspeakers, outdoor parties as well as political public announcements.

- Control Noise level near sensitive areasThere should be control on noise level (Silent zones) near schools, hospitals. Place noise limits boards near sensitive areas.

- Go Green by planning trees- We can plant more trees as they are good noise absorbents. According to studies it can reduce noise by 5 to 10 decibels $\mathrm{Db}$ around them.

\section{Environmental Degradation}

Environmental degradation comes about due to erosion and decline of the quality of the natural environment. It is caused directly or indirectly by anthropogenic activities that extract various environmental resources at a faster rate than they are replaced, and thus depleting them. On this regard, degradation means damage or reduction in quality of environmental features, primarily influenced by human activities. Some natural events such as landslides and earthquakes may also degrade the nature of our environments. Continued environmental degradation can completely destroy the various aspects of the environment such as biodiversity, ecosystems, natural resources, and habitats. For instance, air pollution can lead to the formation of acid rain which can in turn reduce the quality of natural water systems by making them acidic. This is a typical example of environmental degradation. Environmental degradation is therefore a concept that touches on a variety of topics namely deforestation, biodiversity loss, desertification, global warming, animal extinction, pollution, and many more.[5]

\section{Causes of Environmental Degradation}

- Overpopulation and Over-exploitation of Resources - As the human population keeps on enlarging, there is a lot of pressure on the utilization of natural resources. This often causes over-exploitation of the natural resources, and contributes to environmental erosion

- Ruinous Agricultural Practices - Intensive agricultural practices have led to the decline in quality of most of our natural environments. Majority of farmers resort to converting forests and grasslands to croplands which reduces the quality of natural forests and vegetation cover. 
- Landfills- One of the calamitous effects of landfills is the destruction of nearby environmental health together with its ecosystems. The landfills discharge various kinds of chemicals on the land adjacent to forest, various natural habitats, and water systems such as underground and surface water which makes the environment unappealing to the survival of trees, vegetations, animal and humans.

- Increase in Deforestation- The act of deforestation (cutting down of trees) has impacted on the world in terms of depreciating the natural environment and wildlife. It has also impacted on humans on the account of changes in environmental support processes such as weather conditions. Some of the reasons for deforestation include farming, construction, settlement, mining, or other economic purposes.

- Environmental Pollution- Most of the planet's natural environments have been destroyed and a large portion is under huge threat due to the toxic substances and chemicals emitted from fossil fuel combustions, industrial wastes, and homemade utilities among other industry processed materials such as plastics.

\section{Ways to Prevent Environmental Degradation}

- Reduce Our Over All Consumption of Resources - Our natural resources that the planet gives us are limited, but many people seem to forget that. If we cut down our consumption by at least $70 \%$, think of how much we could save. This includes cutting down trees to make paper and other materials that we need, as well as fossil fuels, such as oil, to fuel our cars and keep our industries moving. There are many companies who have already made the switch to go green for the purpose of cutting down their over all resource consumption, such as power, which every company should consider doing. Our wildlife and flora rely on their natural environment, and if we keep tearing it down to serve our needs, we will have nothing left.

- $\quad$ Reuse All the Resources and Materials That We Possibly Can- Second-hand consumption is definitely looked down upon, probably because we know that for what we use, we'll have more eventually. However, this will not be the case forever. Once something runs out, we will never be able to get that resource back. If people start reusing specific things, environmental degradation will be greatly reduced. We all must remember that we do not use the things that were once used before us, which is a scary thought in itself.

- Recycle What We Can, Whenever We CanRecycling is the best way to slow down environmental degradation, and is something that everyone should partake in. If we want to save the planet and take on this mission together, recycling the best way to fight environmental degradation together.

- Green Transportation - If we all rode bikes instead of driving cars, we could combat pollution quite easily. Cars and other vehicles release pollution into the air, which only causes the slow, deadly process of environment degradation to speed up, and cut our time on this planet even shorter. Not only would the air be so much cleaner if we all chose green transportation, such as bike riding to get to where we all need to go throughout the day, but over time we would all be in better shape. Meeting the needs of everyone, especially our planet, when it comes to green transportation is so important, and among one of the best ways to combat environments degradation.

- Give Back to the Environment- The best possible way to help prevent environmental degradation, is to give back to the environment. You can do this successfully by planting three trees for every one that is cut down for the forestry industry. When it comes to the planet's trees, you can never have enough. Trees give us clean air to breathe, they literally filter out the bad and pump out the good, which is why we'd never survive without them. Keeping our forests alive are not only important to our ecosystem, but to the wildlife system of the world as well, because it's their home. When the food chain is affected, we as humans are all affected

\section{Conclusion}

We are aware with the different types of pollutants and their impact on our environment. These pollutants affect humans, animals, plants and atmosphere. Their effects are indeed many and wide- 
ranging. The excessive levels of pollutants cause a lot of damage to human and animal health. For example air pollution reduces the lung functioning, cause irritation of mouth, throat, eyes and nose, asthma, respiratory symptoms like coughing and wheezing.

Air pollutants like sulphur dioxide, oxides of nitrogen etc increases the respiratory diseases and reduces the energy level. Similarly water pollution causes many waterborne diseases like amoebiasis, hookworm, giardiasis, ascariasis and typhoid. The polluted water can damage the nervous system, liver, DNA and kidney.

We can follow green chemistry principles to avoid the pollution at a certain level. Our government implements "command and control" policies in which we try to control environmental pollution with the help of regulating activities which affect the environment. It's high time now. We must follow the guidelines and spread awareness to save our environment to save ourself. If not now, then never.

\section{References}

1. McGeehin, M. A., Qualters, J. R. and Niskar, A. S., (2004). "National Environmental Public Health Tracking Program: Bridging the Information Gap".
Environmental Health Perspectives, 112(14); 1409-1413.

2. Terazono, A., Murakami, S., Abe, N., Inanc, Y. and Moriguchi, S., (2006). "Current Status and Research on e-Waste Issues in Asia". Journal of Mater Cycles Waste Manage, 8, 1-12 3.

3. Betts, K., (2008). "Producing Usable Materials from E-Waste". Environ Sci Technol. 42, 6782-6783.

4. Kumar, Devender; Bharti, Anu, (2017). "Impact of Electronic Waste Leading to Environmental Pollution and Possible Solutions". Globus An International Journal of Management \& IT, 9(1); 1-4.

5. Agarwal, Nidhi and Sharma, Madhu, (2006). "Environment Education Concern in India". University News, 44(12); doi:10.5281/zenodo.3813569.

6. Agarwal, Nidhi; Kumar, Puneet and Mishra, Sugam, (2010). "Need to acquire democratic competency by Teacher Educator in global Scenario". Maa Omwati Journal of Education Research \& Development, 1(1); ISSN:

0976-1365, 